\title{
Musical Extrapolations: Towards an Understanding of Creative Processes Involved While Music is Being Listened to and Composed
}

\author{
Sebastian Schmidt ${ }^{1,2}$ \\ ${ }^{1}$ Independent Researcher, Berlin, Germany \\ ${ }^{2}$ Previously Affiliated to Institute of Musicology and Music Informatics, University of Music, Karlsruhe, Germany \\ Email address: \\ schmidt@hfm.eu
}

To cite this article:

Sebastian Schmidt. Musical Extrapolations: Towards an Understanding of Creative Processes Involved While Music is Being Listened to and Composed. International Journal of Psychological and Brain Sciences. Vol. 2, No. 3, 2017, pp. 69-86. doi: 10.11648/j.ijpbs.20170203.12

Received: April 30, 2017; Accepted: May 9, 2017; Published: July 4, 2017

\begin{abstract}
A systematic understanding is suggested about the conditions, mechanisms, influences, and processes evolving into a creative behavior in music, based on interdisciplinary perspectives of the cognitive sciences: developmental psychology, neuroscience, music psychology, emotions research, and creativity research in general and in music. The focus is on so-called musical extrapolations processes which bring the elusive quality of music into mental existence by creating extrapolations about: first, possible future occurring events; second, their musical meanings; and third, the meanings of their interrelations. These processes, involved while music is being listened to and composed, are defined as the result of implicit and explicit problem-solving processes which are tangibly guided by factors of: intrinsic activities and motivation, pre-disposed and experience-based structures, and environmental pressure. This so-called Model of Musical Extrapolations structures a new perspective in research, and furthermore, provides an enormous potential for future extensions, not least because an enhanced perspective is opened about the complexity of highly creative and parallel processes organizing sounds while listening to what is called music, as well as musical ideas while composing.
\end{abstract}

Keywords: Music Cognition, Musical Creativity, Creativity in Listening to Music, Creativity While Composing Music, Developmental Influences on Musical Creativity

\section{Introduction}

What is Music?

People experience music everyday, and most of them would indeed have an idea of what music is. In fact, the problem is to communicate and describe one's own idea, because music does not have any existence independently of its human perception. A frequently admitted answer communicates musical ideas by describing music, is called music theory. While learning to play an instrument, and consequently to read and understand music semiotics-such as notations, concepts of scales, rhythm, but also culturalhistorical concepts of music - people acquire a terminology, by which it is possible to understand aspects of musical ideas and to communicate aspects of one's own ideas about music to another person. Musicology investigates this cycle, going from music practice and music communication, from different perspectives leading to several findings which can outline aspects of what music is. For instance, a sociocultural perspective [30] outlines answers about what music is for and why individuals listen and practice music. Philosophical perspectives [67] reflect upon the nature of music, such as embodiment, aesthetics, expression, and ethics. Neurophysiological [62] and psychological [58] perspectives investigate what is going on inside the human brain when we develop musical ideas, leading to definitions of the mechanisms and processes of human perception.

The present work opens an additional perspective on the question what music is, namely: the result of ongoing creative processes.

Indeed, music is at first a mental construct. It is only through creative processes, that the physical concatenation of sounds - which is certainly not music itself - can be modeled into certain musical concepts, such as a melody, rhythms, or a musical piece, and ideas about what music is for and why individuals listen to and practice music. 
It can be assumed that the human world is a mental model or an integrated set of hypotheses [56] created by the human nervous system, its current activity, past experiences, and the perceivable environment stimuli. Uncountable studies have been carried out to investigate these conditions and its contribution to creativity, such as the link between creativity and cognition (e.g. [126]), developmental aspects of creativity (e.g. [111]), creative personalities (e.g. [42]), creative production abilities [49], definitions of musical creativity (e.g. [40, 125]), educational strategies for musical creativity (e.g. [75]). However, most of such studies only deal with particular aspects, and relatively little work has been carried out to assess creativity in music in an extended interdisciplinary nature.

The present study proposes such an extended interdisciplinary understanding about the conditions, mechanisms, influences, and processes evolving into a creative behavior in music. Consequently, the goal is to propose a perspective on the question: what are the basic factors and creative processes, which create first, one's own reality while music is being listened to and composed; and second, individuals' psychological developments in musical matters?

\section{Extrapolations - At the Very Heart of Music}

In fact, perceptual, emotional, and social systems in the brain create models or integrated sets of hypotheses about everything we see, feel, and hear. It is this modeling capability that makes it possible both the artist's creation of a work of art and the beholder's re-creation of it. Both derive from the intrinsically creative workings of the brain [59]. Activities of "modeling the world" are so deeply rooted in all facets of life since early infancy, that they do not usually appear at first sight. For example, modeling processes can be seen within perceptual mechanisms of the auditory structuring, because the human nervous system seems to have an innate tendency to group and separate acoustical information out of the ongoing auditory continuum [15]. In addition, every thought or stimulus is probably embedded in a context, which means that individuals try to create complex hypotheses about any given situation. That is to say, our brains use stored memories to constantly make predictions about everything we see, feel, and hear [52].

Consequently, these and later discussed findings suggest a new perspective called musical extrapolations, proposed as a model of creativity in music, and defined as activity, in dependence on a particular context,

1. to predict, based on pre-disposed and experience-based structures;

2. to modify, extend, and combine, based on pre-disposed and experience-based structures.

For instance, at every single instant of listening, exclusively one chord or sound is audible, which in itself is quite meaningless. Only by using memory structures can the elusive quality of music be brought into mental existence by creating extrapolations about:

1. possible future occurring events;

2. their musical meanings;

3 . and the meanings of their inter-relations.

Experimental psychology has shown that processes of creating extrapolations about possible future occurring events have some kind of physical reality: by measuring neural responses after an acoustical event, brain activities can be determined, and hence assumptions can be made about the processing of stimuli (e.g. [72]). By passive exposure, or experience in performing or producing music, 6-year-old children already have acquired a comprehensive implicit knowledge of Western music, which allows them to predict culture-specific aspects of music (e.g. [63]).

Concerning the meaning of music, although many composers believe that the meaning of music is the music itself and nothing more ([24], cited by [60]), meanings at a psychological level are important for individuals, and moreover different, even contradictory, levels of interpretations, emotions and other meaningful experiences can arise on the basis of the same physical sound [118].

In this way, it seems that creating extrapolations about musical meanings are mainly supported by three factors:

1. first, through pre-disposed structures, such as perceptual mechanisms of auditory structuring (e.g. grouping, stream-segregation). These involve:

2. experience-based structures activated in the current situation;

3. the current mental state: e.g. the degree of general wakefulness or tiredness, paying attention to a particular point of interest, including motivational aspects, and particular mood and affect states, which seem to support certain cognitive processes.

It can finally be assumed that extrapolations about possible occurring events in time, their musical meanings, and the meanings of their inter-relations, are not separate processes, but interconnected and mutually dependent. In accordance with the first definition of musical extrapolations (see above), it can thus proposed that in a certain context it is possible to predict occurring events in time, based on pre-disposed and experience-based structures.

These events always possess a particular kind of meaning due to their projection because, as it was seen, extrapolations about musical meanings are based on the supporting factor of experience-based structures, which can be defined as structured meanings. These meanings again presuppose particular inter-dependencies, or, that is to say, inter-relations of musical meanings, which in their turn can appear by extrapolations about possible occourring events in time.

This raises the question: How are experience-based structures created or developed, as well as the ability to predict events, their meanings, and the meanings of their inter-relations?

To anticipate an answer (details follow later), an individual's developmental process of experience-based structures probably takes place in a kind of cyclical interplay of processes included in both definitions of musical extrapolations (schematically seen in Figure 1). 


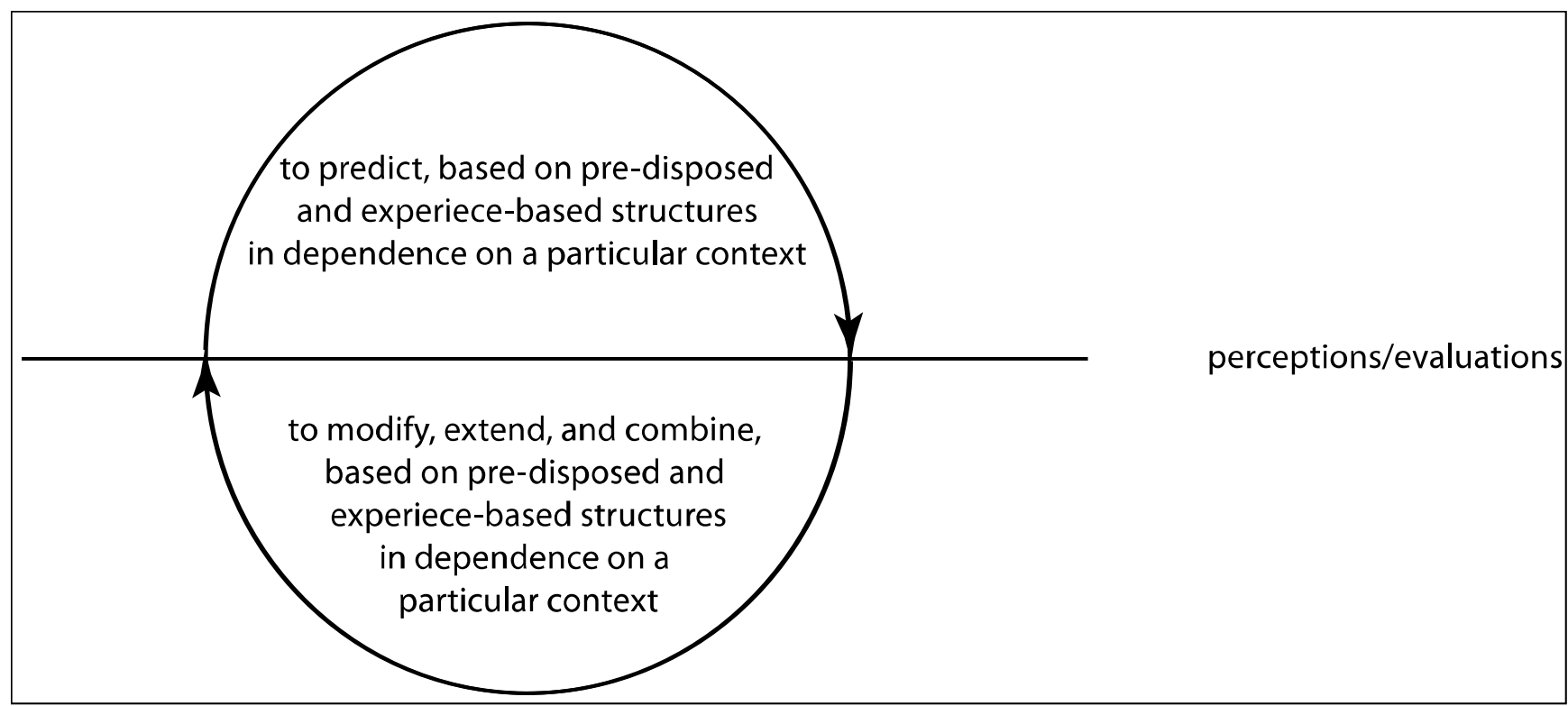

Figure 1. Cyclical interplay of both kinds of musical extrapolations.

This means that, based on pre-disposed and experiencebased structures, when predictions or hypotheses in dependence on a particular context are not evaluated as satisfied and/or are not compatible with current perceptions, then predictions or hypotheses are modified, extended, and combined in a certain way.

When these new predictions or hypotheses achieve a certain kind of satisfaction during perceptions and evaluations, then this working mental model can be used to extrapolate its containing meanings and inter-relations in a particular context.

It is obvious that the proposed underlying processes seen in Figure 1, which foster psychological development, are too simplified to explain complex creative processes and varied development opportunities in relation to music.

For example, all infants are per se pre-disposed for music, because around one year after birth, they can process nearly all acoustical parameters, and can mentally organize these parameters - although in a limited fashion (see below). Furthermore, that creativity, as potential, is given all infants from birth. This is seen when infants create/transform new meanings from sense impressions. Despite this, not every child is fascinated enough to experiment with all kinds of sound sources, try to acquire and learn musical instrumental techniques, begin to compose music and later develop an understanding about what can be H-creative [12] in the domain of music, and attempt to compose $\mathrm{H}$-creative music.

Therefore, if one tries to conceptualize a more comprehensive description of creative processes in relation to music, it is necessary to incorporate further factors and describe their interactions, such as intrinsic activity and motivation, biological maturation, and various enviromental influences, organized in a Model of Musical Extrapolations. Furthermore, processes of creating musical extrapolations must be defined more precisely than: 'to predict' and 'to modify, extend, and combine, based on pre-disposed and experience-based structures in dependence on a particular context'. This means, based on several findings within perspectives of creativity in general (e.g. [121, 47, 25, 122, 78, 91, 22]), and in terms of music (e.g. [40, 39, 61, 125]), as well as creativity in listening to music (e.g. [97, 35, 29, 85, 98]) and creative processes while composing music (e.g. $[9,108,110,124$, $16,17,23]$ ), that musical extrapolations of 'predicting, modifying, extending, and combining' include processes of problem-construction and problem-finding, ideageneration, but also evaluation processes.

Hence, a coherent structuring of these (and other) factors and processes into a Model of Musical Extrapolations will be subject in the next chapter.

\section{The Model of Musical Extrapolations - Basic Factors and Their Inter- Dependencies}

An original proposal of musical creativity is presented (see Figure 2), which generally proposes that processes of problem-construction and problem-finding generate mental models or integrated sets of hypotheses ${ }^{1}$ depending on a particular context or a synchronic environmental pressure. These processes are driven by intrinsic activities and motivation, and supported by so-called pre-disposed and experience-based structures.

1 For detailed information about the concept of mental model in the concerns see section, Processes at the very Heart of Musical Extrapolations. 


\section{Model of Musical Extrapolations - Basic Factors and their Inter-dependencies}

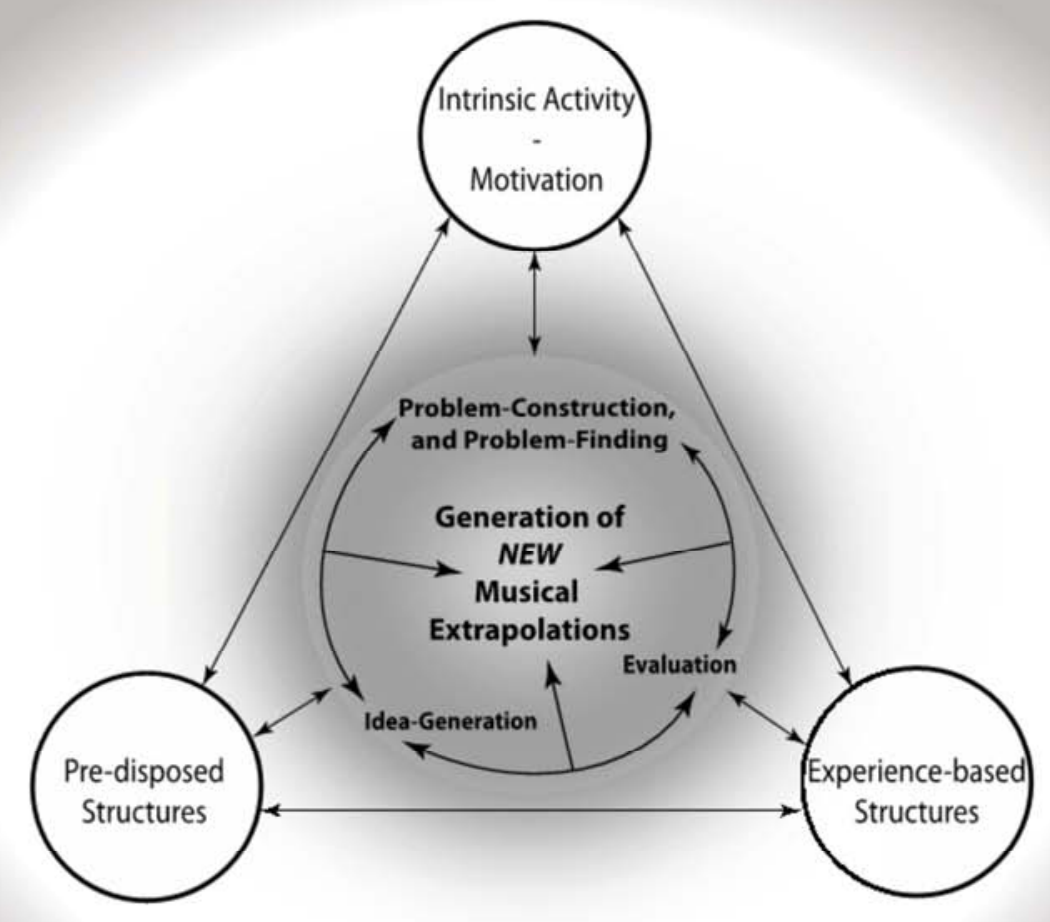

Individual

Figure 2. The Model of Musical Extrapolations.

Based on these models or integrated sets of hypotheses, and their interplay with processes of idea-generation and evaluation, music can be brought into a kind of mental and composed existence by creating extrapolations about: first, possible future occurring events; second, their musical meanings; and third, the meanings of their inter-relations. The subsequent sections explain in detail the proposed Model of Musical Extrapolations, basic factors, and their interdependencies.

\subsection{Intrinsic Activity and Motivation}

At a very basic level in humans a kind of intrinsic activity exists which constantly strives to organize the chemical parameters of a body's interior (its internal milieu) within the magic range compatible with life - called the homeostatic range -, which changes when the current state is out of balance [74]. Because, attempting to correct homeostatic imbalances after they begin is inefficient and risky, during the course of evolution, devices and mechanisms have emerged, which allow organisms to anticipate imbalances, or, can predict whether a possible occurring event or situation is useful or dangerous for the organism [26]. Indeed, prediction activities seem to be a fundamental intrinsic activity in the most animals and all humans [51]. In the case of humans, it can be assumed its pre-implemention in the human genome, which starts in fetuses as soon as brain structures are interconnected (e.g. [33]) - between the 29 and 33 week of gestational age, fetuses' nervous systems ongoing predict the last perceived acoustic stimulus [72]. Prediction is apparent in fetusus' and infants' processing of acoustical stimuli [120] and has been implicated in infants' threshold sensitivities (e.g. [127]), infants' pitch discrimination abilities (e.g. [54]), and abilities to group and segregate auditory information (e.g. [129]).

In addition, during the course of evolution, highly specialized sense organs and well-developed nervous systems 
have been formed, whereby it is possible, not only to predict current changes in the environment, but to incorporate a broad amount of pre-disposed and experience-based structures (details follow later) to extensively explore and interact with the environment. Such more complex intrinsically motivated activities - conceptualized as play can be observed very well in infants, when they construct or discover the environment.

That is to say, playing constitutes an intrinsic activity per se, whereby (not only) infants explore unknown structures. Therefore activities of play were defined as important factors for individuals' psychological development (e.g. [86]). In musical terms, numerous indications for such a perspective can be found, e.g. play drives individuals' development towards processing and producing sounds (e.g. [50]), and, seems to be in general intrinsically bound up with all artistic activity [110].

However, because, intrinsic activities of play seems to be too limited to conceptualize comprehensively the force which drives individuals' to extensively work (and play) in the musical domain, their fascination to repeatedly create or solve musical problems, to try to develop ideas for possible solutions, and thus, in dependence on a particular context, repeatedly predict and modify, extend, and combine based on pre-disposed and experience-based structures in dependence on a particular context, the motivation concept [21] must be incorporated, whereby it is possible to explain, among other, initiation, direction, intensity and persistence of creative behavior, especially goal-directed behavior, such as creative problem-solving activities (e.g. [130, 91]).

Finally, it can be concluded that drives conceptualized as intrinsic activity and motivation occupy a central place within the Model of Musical Extrapolations (see Figure 2). Indeed, these drives strongly affect all factors and processes within the proposed model, and, by that, affect individuals' psychological development while handling with the musical phenomenon during listening and composition as well.

\subsection{Pre-disposed Structures}

The factor pre-disposed structures reflects an important concept, because humans base their intrinsic activity and motivation on so-called pre-disposed structures, which are present and function already before and immediately after birth and evolve through a kind of biological maturation. Generally, pre-disposed structures define all those structures in humans, which seem to be innate or pre-disposed in their basic structure, and can physiologically and psychologically process (not only) acoustical information in a comprehensive manner. Indeed, fetuses possess broadly working structures, which allow to respond to music-relevant information such as a wide range of frequencies [55], changes of musical notes [70], melodic contour [45], tempo variation [66], as well as recognition of human voices [28], and discrimination between their mother's and a stranger's voice [65]. Furthermore, fetuses possess innate mechanisms which group and segregate acoustic stimuli [129], and, at about the 29th week of gestation age, they possess limited auditory memory structures [120, 46, 119] - both structures together are necessary to detect changes in frequencies, notes, melodies, voices.

Regarding the biological maturation of these capabilities, there are strong indications that, within a relatively short time after birth, infants develop an enhanced sensitivity in structures contributing to the discrimination between frequencies (e.g. [83]), pitch (e.g. [77]), and timbre (e.g. [117]), as well as processing of pitch (e.g. [112]), and temporal pattern (e.g. [68]), and of auditory threshold (e.g. [116]).

If one now relates pre-disposed structures to creative processes at the very heart of the proposed Model of Musical Extrapolations - defined as problem-construction and problem-finding, idea-generation, and evaluation (details follow later), it can be assumed that to construct a problem from an auditory perception, and by that, to evaluate the current perception in relation to previously generated extrapolations, one must refer to further mechanisms, which are essential for such processes, and furthermore seem to be innate or pre-disposed in their basic structure. This means, because humans have access to a neuro-physiological state that is consciously accessible as a simple, non-reflective feeling, from which, and in relation to a perceived stimulus, an affect is generated [93] - such an emotional experience can change the degree of intrinsic activity and motivation (e.g. $[92,95,3,19])-$, it is obvious that intrinsically grouped frequencies, pitches, timbre, auditory thresholds, organized into simultaneous and sequential pitch and temporal pattern, get assigned an extended meaning by simultaneously evoked affects, resulting from current perceptions put relation to preceded (primitive) models or integrated sets of hypotheses and their extrapolations about the current context - such a process is part of problem-construction and evaluation processes. This in turn implies however, that pre-disposed structures generating an affect or an emotional experience, in relation to certain grouped acoustical information, reflects initial cues for experience-based structures.

This fact implies that processes of creating initial experience-based structures must be explained by a constructivist model of creativity, means, at the origin of fetuses' creative experience, aiming to construct and discover (among other) the acoustical environment, there are no experience-based structures. Fetuses must create these structures! Based on the proposed Model of Musical Extrapolations, a possibility is offered of describing how fetuses create these initial experience-based structures in terms of acoustical information.

This means, at about the 29th week of gestational stage, fetuses' central auditory pathways are myelinated with the brain stem [84]. At the same time, fetuses possess limited memory structures wherein acoustical information can be saved. Fortunately, it was found that the start of working sensory-memory structures in fetuses is associated with the intrinsic activity to predict, or, that is to say, each sound forms a memory trace in the auditory system, if an incoming sound violates the neural memory representation of the 
recently heard sounds, it elicits an event-related brain potential called MMN [69]. This working mechanism is very informative, because it reflects an intrinsic activity in the auditory system for predicting future sound events on the basis of the recent past, and the brain's reaction when those predictions are not fulfilled [114]. These processes can be defined as highly creative. In addition, they produce initial experience-based structures. This means that, by the intrinsic activity and motivation, pre-disposed structures detect and organize the ongoing auditory continuum into coherent auditory events, whereby the perceptual system can orient itself within the sound domain, and in some sort define it. In the Model of Musical Extrapolations, these processes are called: problem-construction and problem-finding. Based on this, the auditory system generates a very limited explorative guess. In a certain way, it predicts the last sound. This extrapolation will be evaluated in relation to subsequently defined (perceived) sounds. If current extrapolations are violated by actual perceptions, then new experience-based structures are built, in such a way that a new and different future perception is expected. The next time, during this performative process, sounds are associated to each other, simply because they follow each other within a short time delay. Thereafter, the newly learned association between distinct sounds can be further used to predict upcoming events, especially when this connection is strengthened (e.g. by repetition).

These processes define the groundwork for a developing cognition in music. Initial (primitive) mental models or integrated sets of hypotheses are constantly modified, extended and combined into gradually more complex models, coded in memory as kinds of experience-based structures.

\subsection{Experience-Based Structures}

Experience-based structures are defined as generated musical extrapolations coded in memory mainly in two modes: declarative knowledge and procedural knowledge.

Furthermore, it is proposed that in order to organize mental models or integrated sets of hypotheses about current perceptions, and by that, to be in process of generating musical extrapolations, activated experience-based structures facilitate to this, in the form of abstract relations represented in a concrete imaginable situation.

To go more in detail, declarative knowledge includes facts, categories, schemas, concepts, and relationships between them, which reflect an extended understanding in a certain domain of knowledge [2]. This means in terms of music that for example during perceptual categorization, the ongoing auditory continuum is structured into coherent auditory events, which reflects an important mechanism to built up initial meanings. Based on this, basic structures of experience, so-called conceptual categories, are organized in memory, which allow to identify and generalize perceptual categories, and, link stored perceptions together, occurred at different times. Furthermore, categories are essential to build schema about acoustic/musical matters, or, that is to say, categories are the elements or slots from which schemas are constructed [107]. Indeed, schemas store abstracted knowledge about relationships of concepts, and experiences in different situations and at different times, that have some common aspects.

In addition to these sketched cognitive structures, emotions can also partly be defined as a kind of declarative knowledge, because often they will be coded to certain cognitive structures, and by that, specify and differentiate their meanings [93].

These facets of memory structures, characterized as declarative knowledge, are very important for organizing current acoustic/musical perceptions, means, the understanding of situations, relations of schemas, concepts, categories, and related emotional experiences, are used to organize current mental models or integrated sets of hypotheses about certain perceptions. Activated declarative knowledge also effects the intrinsic activity and motivation in musical extrapolation processes (see Figure 2). For instance, if explicit emotional memories were coded to this knowledge, e.g. negative affect, an interpretation of this activated emotion can increase the motivation, such as trying harder to generate creative ideas for solving a constructed problem (e.g. [73]).

Procedural knowledge represents the second mode, wherein musical extrapolations coded in memory. As declarative knowledge, procedural knowledge help to organize current perceptions and actions, but, furthermore, reflects a procedure which organizes how we think [2]. Activated procedural knowledge cannot easily be articulated by individuals, because it is mostly exercised unconsciously. For example, if one ask a pianist to describe the procedural knowledge he/she exercises while performing a certain piece of music, he/she certainly has problems to articulate these knowledge.

Indications can also found that procedural knowledge can possess emotional structures [20]. Such so-called emotional procedures seem to be very important for creative processes, because they often have decisive influence on the direction of extrapolations while listening to music and composing too. For example, composers' compositional processes are guided by exercised emotional procedures. First, sound perceptions are supported by activated affects - bodily reactions, such as muscle tension, or changes in blood pressure and heart rate [71] -, which were stored in conjunction with previous acoustical perceptions [82]. Such coded patterns of affects, or emotional procedures, influence and process the meaning, significance, or value of a stimulus to the individual [18]. Second, emotional procedures seem to be in general conducive for composers' attitude to work. Because, if performed emotional procedures 2 culminate in an emotional state which is consciously accessible, then it was shown that the quality and type of cognitive processing can be influenced.

\footnotetext{
2 An emotional procedure can also be termed as a scheme of action that is performed while composing, and is familiar and comfortable for the composer, e.g. to compose at the piano.
} 
Furthermore, it is important to state that a composition task can not be performed only by means of declarative knowledge about the composition of music and its associated emotional aura. The frequently used example of a germinal idea [9, 108] which will gradually be elaborated into a structured composition can only be realized in relation to procedural knowledge and emotional procedures, and by using techniques, methods, and strategies to elaborate interesting compositional problems and to solve them in a satisfactory fashion.

In terms of maturation of both memory structures, indications can be found from the cognitive science that procedural and declarative knowledge are fully present at different phases in the development of individuals. This means, fetuses possess a limited procedural memory already at 29th week of gestational age [46], and procedures are limited present before birth [64, 57]. But the declarative memory system does not emerge until the end of infancy [96]. One reason for the missing declarative memory system seems to be that involved pre-disposed structures are immature, particularly the postnatal hippocampus [80]. This perspective can be verified in terms of some aspects observed at the beginning of individual's creative experience with music, such as infants' temporal abilities develop from perceptual and motor procedures [113]; practiced motor procedures such as sucking rate [115] are essential foundations to predict time and rhythmical structures in musical terms [32]; infants up to 3 years do not use declarative knowledge while are engaged in music - assumed by their unsteady and unorganized musical play [110]; and, approximately at the age of five, children are able to schematically recognize and use artistic conventions, and begin to compose more melodic and rhythmic patterns as well as the apparition of musical conventions, such as musical phrases and meter [50].

Further generalizations about declarative and procedural knowledge can be made, based on the interpretation of findings of music psychology and creativity research. From the perspective of music psychology, it can generally be assumed that saved memorized structures lay the very foundation of musical extrapolations, based on the fact that individuals can recognize that there exists a gap or a musical problem which is interesting enough to spend some time on (e.g. [39]). This points at the fundamental character of experience itself. It is the groundwork for individuals' further development: based on previous experience-based structures, new experiences are created, and the knowledge is built which can be used to recognize that there exists a gap or a musical problem. This implies two things: although child prodigies are found in music history, e.g. Mozart, first, the construction of knowledge is constrained through a kind of individual biological maturation $[87,50]$; and second, $\mathrm{H}-$ creative efforts [12] require a previous period which evolves musical extrapolations which can be characterized as Pculturalized-musical creativity 3 . In creativity research,

3 It can be suggested that infants start from a sort of P-musical-creativity which, indications can also be found for the fact that experience is the 'the groundwork for individuals' further development building an important factor for possible H-creative efforts, means, increases in the degree of expertise or experiencebased structures occur frequently in correlation with increases in H-creative efforts. This can be seen by the fact that most famous discoveries, inventions, or works in art are products of creative thinking and behavior during adulthood. Indeed, musical creativity research presents indications for the perspective that activated declarative and procedural knowledge is essential for creative efforts, such as a firm grounding in the basic skills of aural discrimination may be important in establishing a basis for creative ability (e.g. [123]); individuals who were rated as highly creative composers were more aware of temporal factors than their middle and low counterparts (e.g. [89]); and, composition students with limited formal tuition in music produce a minimal setting of constraints while decision-making moments (e.g. [16]).

Finally, this outline of so-called experience-based structures can be extended by arguments which indicate, that in addition to essential domain-specific knowledge or experience-based structures, in domains that are less logically ordered, such as musical composition, literature, and philosophy, specialized knowledge is not enough; one needs to reflect on a great amount of experience before being able to say something new (e.g. [81]).

\subsection{Environmental Pressure}

As schematically seen in Figure 2, the concept of environmental pressure reflects all possible information which can be detected by pre-disposed structures, and supported by activated experience-based structures. Detected information will be organized in so-called mental models or integrated sets of hypotheses, among other, to build the current environment with its meanings.

This implies that there is no one environmental pressure, but many possible, individually constructed pressures. And further, that music listening experiences, but also composers' experiences while conceiving a musical product, are a part of a personal synchronic environmental pressure created by individuals. The creation of a so-called synchronic environmental pressure strongly depends on the current intrinsic activity and motivation, and its related emotional aspects. This means, besides the degree of general wakefulness or tiredness (physical or mental), individuals, which possess a highly intrinsic motivation to extensively work (and play) in the musical domain, are highly focussed on music-related stimuli, and their organizations in mental models or integrated sets of hypotheses to create musical extrapolations, and, by that, process a P-culturalized-musical creativity (e.g. [4]).

Beyond intra-individual processes forming a personal synchronic environmental pressure - with its musical parts -,

during an ongoing practice, usually leads to a more P-culturalized-musicalcreativity. 
certain organizational structures must also be present in the current environment, which will be perceived and foster intra-individual processes. Such organizational structures are most important factors, guiding individuals' creative experience or their psychological development (not only) in dealing with music.

This suggests that parents, caregivers, siblings, the inner family life, musical mentors and role models have a crucial impact on children's and students' available organizational structures, and, by that, influence the directions of the personal synchronic environmental pressures created [94]. Furthermore, intrinsic activity and motivation as well as flexibility can be assumed as two key features for the processing of environmental organizational structures. This again suggests, in terms of individuals' musical extrapolations, that parents, musical mentors, should try to stimulate intrinsic activity and motivation as well as flexibility by presenting interesting alternatives or organizational structures, such as to allow to listen to different music, to encourage to learn a music instrument, to show and talk over musical subjects as well as to outline possible structures of musical pieces, but also, to present enhanced perspectives from philosophy, religion, and culture, mediate varieties of tactics and strategies for reaching goals, and let children and students make mistakes.

\subsection{Processes at the Very Heart of Musical Extrapolations}

In the final step, processes are defined which are in play at the very heart of the Model of Musical Extrapolations, namely: problem-construction and problem-finding; ideageneration; and evaluation (see Figure 2).

This means, the core of the Model of Musical Extrapolations consists in processes which, in relation to each other create the music as a mental construct while listening and while composing, and simultaneously put forward individuals' P-culturalized-musical creativity.

Defining musical extrapolations as processes establishing musical mental constructs points towards a further assumption. It was frequently suggested that musical extrapolations are organized as mental models or integrated sets of hypotheses. This is an useful description, because, first: telic functions of mental models can be put forward to describe listening and composition activities. Second, within the concept of mental models, one can integrate complex information processing, as discussed previously in paragraphs on intrinsic activity and motivation, pre-disposed structures, experience-based structures, and environmental pressure. For example, within the so-called perceptual auditory processing, the intrinsic activity related to predisposed structures of individuals processes out information from the surrounding acoustic continuum, and thus, model the acoustic environment. But also, the intrinsic activity of fetuses 'predicting' future sound events based on the recent past, reflects the ongoing modeling of at least two information together with their relations. In the further psychological development of individuals, as it was shown, the modeling of acoustic information becomes increasingly complex.

This is possible because activated declarative and procedural knowledge organize mental models or integrated sets of hypotheses for certain purposes in relation to current acoustic perceptions. This can be seen very early in terms of listening to music: 6-year-old children can predict culturespecific aspects of music, such as tonal and harmonic regularities [63].

Indeed, in the case of musical extrapolation processes while composing of music, mental models are essential to create new musical structures, and seem to include two aspects: First: musical imagination allowing to mentally hear desired sounds and their alteration - Bailes and Bishop [7] systematize indications for such a perspective. And second, instantiations of more abstract schemes, concepts and possible relations, such as scales, rhythms, tensions, phrases and their proportions and variations, the overall structure of the composition, but also concepts external to the musical domain, such as philosophy, religion, literature, visual arts. For instance, composers' germinal ideas [9, 108], which often initiate new compositions, are more or less precise organized mental model about relations of musical structures, based on pre-disposed and experience-based structures. Such an organization process allows the composer to mentally hear (and in a certain way to predict) a germinal idea. Furthermore, this model is the design basis on which the composer can develop further thoughts to forward his compositions, and by that, modify, extend, and combine, incorporate abstract schemes, concepts in order to develop germinal ideas into more and more elaborate composed structures.

To go more in detail, the subsequent paragraphs outline creative processes which generate and structure these socalled musical mental models or integrated sets of hypotheses. However, these proposed processes are no explicit stage-to-stage processes - from problem-construction and problem-finding to idea-generation to evaluation - but have to be conceptualized as cyclical, including simultaneous, recursive processes.

\subsubsection{Problem-Construction and Problem-Finding}

Initially, it can assumed that the nervous system of humans, in its function, is telic [1]. Furthermore, a problem can be defined as a situation with a goal and an obstacle. The individual wants or needs something (the goal) but must first deal with the obstacle [94]. In addition, as proposed above, individuals possess and perform an intrinsic activity, 'to predict: first, possible future occurring events; second, their musical meanings; and third, the meanings of their interrelations' 4 . This means, while listening, individuals constantly anticipate and conceive forthcoming musical structures, and that, while composing, possible forthcoming musical structures are conceived.

Consequently, it can be synthesized that a so-called problem arises, when a complex of differences or tensions is

4 First definition of musical extrapolations. 
constructed between previously generated musical extrapolations (representing a sort of goal) and current perceptions and evaluations (comparable to obstacles). This suggests that the term problem is a place holder for complex neuro-physiological and psychological processes which drive the intrinsic activity and motivation to practice Pculturalized-musical creativity, or, that is to say, to modify, extend, and combine, based on pre-disposed and experiencebased structures, in dependence on a particular context ${ }^{5}$.

Referring to comprehensive findings of Snyder [107], one can suppose that at the very basic level of acoustic information processing, based on pre-disposed structures, various kinds of problems are constantly constructed and solved, such as to extract features, perceptual binding, stream segregation, grouping processes [15].

An example for processes constructing higher-order problems while listening to music can be seen by the example of Haydn's Symphony no. 94 - nicknamed: Surprise Symphony. Haydn composed the first phrases of the main theme almost completely in the dynamic level piano. But, at the end of the second phrase, he writes an untypical isolated fortissimo chord occurring on the weaker second beat. For listeners, such organizational structures can construct some kind of problem: previously generated musical extrapolations in terms of schemes, concepts, categories do not match current perceptions. As a consequence from this difference or tension, some kind of problem is constructed, illustrated by the highlighted affect which can modify the intrinsic activity and motivation involved in finding the problem.

Finally, it can be concluded that while listening, a constructed problem - which can be reflected by a generated affect - activates processes which try to modify, extend, and combine information within current so-called mental models or integrated set of hypotheses in order to solve this problem (of understanding). That is to say, processes of problemconstruction cause a re-organization of current mental models or integrated sets of hypotheses, in the form of enhanced involvement of experience-based structures, as well as detection of further environmental organizational structures, and, by that, cause a telic activity to generate ideas in terms of: first, possible future occuring events; second, their musical meanings; and third, the meanings of their inter-relations.

The composition process can also be characterized as being confronted to various kinds of problems. However, the nature of problems constructed by listener and composer differ significantly in structure, time exposure and complexity. For example, composers must extrapolate musical meanings, inter-related, and structured in time, from ill-defined problem-spaces (e.g. [78, 99]). As for listeners, emotional experiences play an important role in constructing problems for composers, rather than merely finding problems. This happens because, among other, these experiences influence attention, perception, thinking, judgment, storage, mental simulation, and retrieval from memory (e.g. [8, 11, 13, 38, 43, 44]).

5 Second definition of musical extrapolations.
These effects have implications of two sorts: first, current affects signal and, by that, construct some sort of problems, when a complex of differences or tensions arises between previously generated musical extrapolations and current perceptions and evaluations; and second, the current mood state - for example arisen after the construction of a larger problem - effects the overall motivation for possible problem-finding and problem-construction processes.

Furthermore, a mildly depressed mood or affect state can be seen as very conducive for the composing process. Because, this state can increase the intrinsic activity and motivation for the ongoing re-organisation of perceptions in relation to activated experience-based structures, in order to find and construct new problems - assuming that composers having in mind the goal of successfully completing their compositions.

Finally, based on earlier discussed findings from cognitive science and developmental psychology in terms of music, it can be stated that processes of problem-construction and problem-finding ultimatly depend on experience-based strucutures as well as maturation of pre-disposed structures. Because as discussed above that under the age of five, declarative knowledge - as a part of experience-based structures - can not be coherently coded in memory. And, during the psychological development of an adult, phases can be defined, in which individuals usually possess different skills in constructing, finding (and solving) various sorts of problems (e.g. $[10,50,110,100])$.

\subsubsection{Idea-generation}

As seen in Figure 3, processes of idea-generation or ideation can initially be differentiated into more convergent and more divergent ideation happening while individuals solve constructed problems, or, while they are trying to find problems.

At a general level it was seen, that the nervous system of humans, in its function, can be defined as telic, assumed that its basic function is to protect the body against a worst-case situation. Hence, an automatically generated behavior to protect the body, presupposes a certain kind ideas or processes, which generate suitable responses to constructed problems. These processes can be defined as more convergent ideation, because convergent ideation coordinates processes, aiming more in the direction of a single-precision solution. This in turn means that when an idea is generated in terms of a suitable protective motor scheme, the nervous system 'predicts, based on pre-disposed and experience-based structures in dependence on a particular context' (see Figure 3) forthcoming perceptions, and tries to prepare the body to react adequate. Such a convergent mechanism predicting possible stimuli is very essential. It was defined previously as individuals' ongoing intrinsic activity, which fetuses already perform in a limited fashion (in terms of acoustic stimuli), and furthermore, develops rapidly in a very short time after birth. For example, 6- year-old children already have acquired a comprehensive implicit knowledge of Western music, which allows them to predict culture-specific aspects of music, such as tonal and harmonic regularities. 


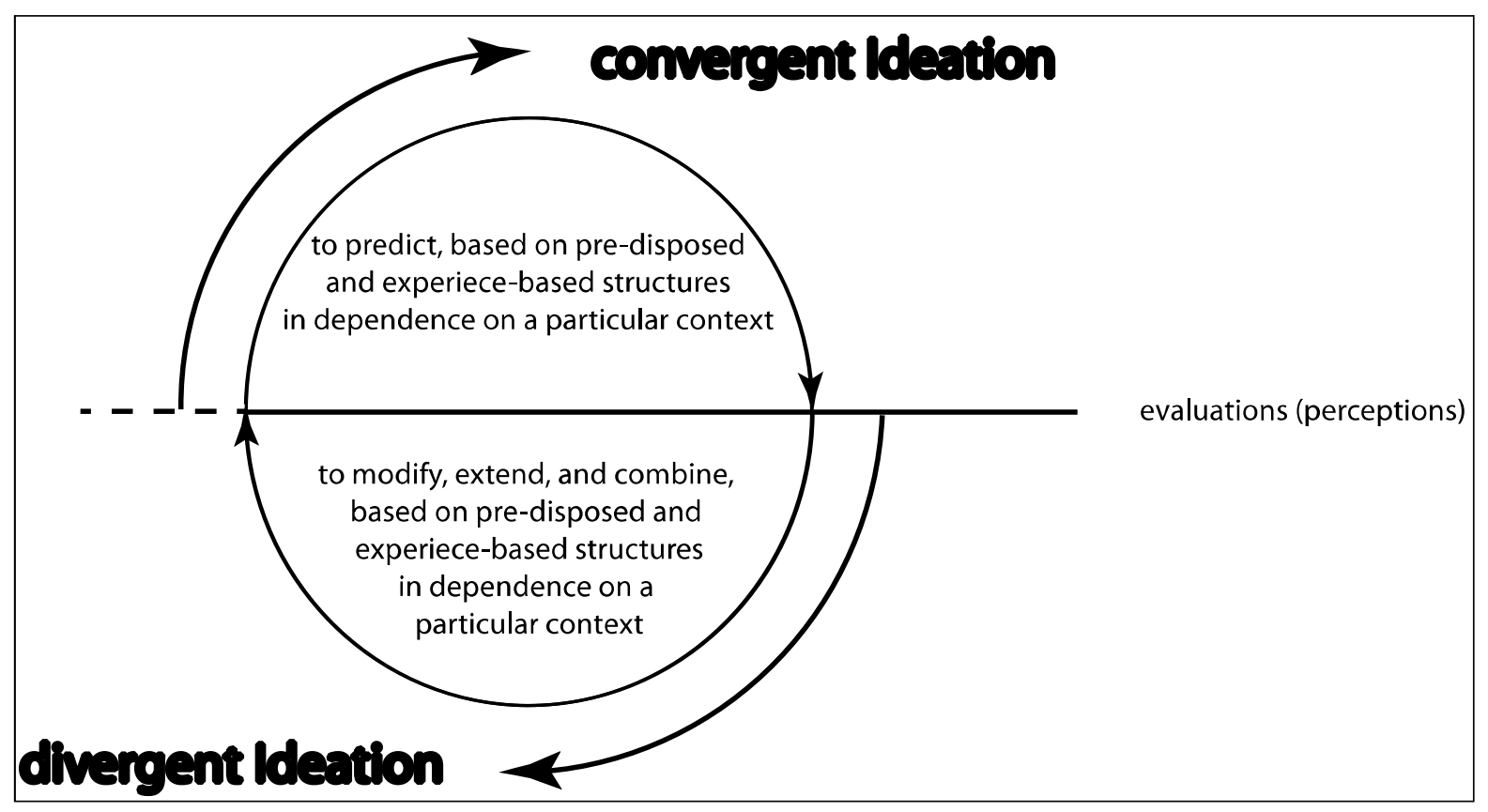

Figure 3. Cyclical interplay of different Idea-Generation processes.

Moreover, by activation of experience-based structures often more convergent ideation are caused automatically. In terms of music, instantiations of one ore more schemes, concepts, categories, and related emotional experiences automatically organize sounds to so-called musical mental model or integrated set of hypotheses. And this mental organization automatically generates kind of ideas directed towards: first, possible future occurring events; second, their musical meanings; and third, the meanings of their interrelations. To illustrate such an ideation found in listening to music, indeed at the end of Haydn's main theme discussed above, the experienced surprise, arisen when an untypical isolated fortissimo chord is played on the weaker second beat, reflects a constructed problem, caused by evaluation processes, which have detected differences or tensions between a generated ideation about future occurring events and the current perception of that loud acoustic stimulus.

In addition to more convergent ideation which are often automatically processed while listening to music, convergent ideation processes can also be structured from evaluation processes, which try to whittle down, combine, or select consciously or unconsciously - more divergent ideation processes into or as a most feasible idea (see dashed line in Figure 3). The conception of more divergent ideation processes based on Tuuri and Eerola's [118] taxonomy of listening modes, which suggest a potentially divergence of ideation processes occurring in every listening situation. In this way, it can be specified that acoustic stimuli, organized by experience-based structures, offer various possibilities for individuals to intentionally re-organize them into divergent ideations at certain moments while listening - Incidentally, such processes offer a possible explanation of why people construct their very own personal environmental pressure while listening to music.
That is to say, more divergent ideation processes while listening can include experiential ideations (reflexes, kinaesthetic qualities, associative mental images), denotative ideations (causal, empathetic, functional and semantic listening), and reflective ideations (reduced and critical listening). In addition, different sorts of ideations, or divergent ideations, such as reflexive, kinaesthetic, denotative ideation, can be related or combined into a more convergent ideation - at a single moment while listening!

This also reflects information about: first, possible future occurring events; second, their musical meanings; and third, the meanings of their inter-relations. Thus it can be concluded that the cyclical interplay (see Figure 3) of both, more divergent ideation processes in relation to more convergent ideations, creates personal mental models or integrated set of hypotheses about the music which is listened to, or, in other words, both processes organize the elusive quality of sounds or chords, which have occurred at different times, into music. This is precisely what music actually is: a mental construct.

Let us turn to the ideation processes during the composition of music. First at all, it can be assumed that the nature of problems constructed by listeners and composers differ significantly in structure, time exposure, and complexity. This suggests that ideation processes occurring while listening and composing differ significantly in structure, time exposure and complexity as well.

Notwithstanding these enormous differences between ideations while occuring listening and composing, composers' ideations, can also be conceptualized into a cyclical interplay of more divergent ideation processes in relation to more convergent ideations.

This means first, that compositional processes of problemconstruction and problem-finding often initially cause more 
convergent ideations automatically ${ }^{6}$, such as a created germinal idea, a plan or a framework, a scheme, a texture, an image of a sound - defined as a solution to a constructed problem. Arguments can be found for such a perspective from creativity research (e.g. [79]), music psychology (e.g. [9]), and not least from a statements of composers (e.g. Richard Strauss, cited by [108]).

In addition, because composition is additive in nature there are ever emerging and proliferating points of origin [23], more convergent ideations usually cause subsequent new problem-construction and problem-finding processes. This means, individuals construct a problem based on tensions or differences between previously generated ideations and current perceptions and evaluations. These subsequent constructed problems may have different objectives, such as a revision of the current solution, the expansion of that solution, or a problem that addresses a different compositional detail. For all such problems, it can be assumed however that composers usually process more divergent ideations, or, in other words, they usually modify, extend, and combine, based on pre-disposed and experiencebased structures, in dependence on a particular context (see Figure 3). An important role play positive affects and mood states for the potential of more divergent ideation. Indeed such states increase the potential of ideational fluency, combinational thinking, divergent thinking, and transformational processes of existing knowledge into new patterns of configurations (e.g. [101, 102, 103, 104]). Furthermore, a musical mental model or integrated set of hypotheses of a germinal idea, texture, sound, in terms of acoustic stimuli offers divergent possibilities for composers to generate ideations from it, such as kinaesthetic ideations or denotative ideations, or kinaesthetic-denotative ideations.

Not least, divergent ideations for compositional purposes are mostly characterized by transformations and combinations. This means, composers try to transform and combine non-musical and/or different musical concepts into meanings of acoustic stimuli [27], and by that, try to develop more divergent ideations as possible compositional solutions. This perspective could also be supported by findings from cognitive sciences, because probably every compositional innovation is characterized by transformations and combinations of pre-existing declarative and procedural knowledge. This means that abstract knowledge, such as schemes, concepts, categories, emotional procedures must intentionally be combined and transformed to organize the concrete compositional situation. Furthermore, there are uncountable musical works which are obviously based on conceptual transformations or combinations. At a macro level, the border crosser John Cage transformed concepts from philosophy, visual arts, literature, music, danceperformance for his musical compositions. Arnold Schoenberg developed a transformation of the Western music

6 This is because instantiations of one ore more scheme, concepts, categories, and related emotional experiences automatically organize sounds to musical mental model or integrated set of hypotheses. pitch system, but keeping the established pitch-spacings, instruments, rhythms. Iannis Xenakis combined stochastic phenomena with acoustic stimuli, and by that, created the socalled Stochastic Music.

Finally, if one relates Guilford's [49] four components of divergent production abilities, identified as: fluency, flexibility, elaboration, and originality, to the present concept of so-called more divergent ideation processes during listening and composition. It can be emphasized that flexibility in the processing of organizational structures is one of the most important precondition for creative efforts. One can agree that, at a certain degree, people must necessarily think fluently to achieve compositional goals in a short time. However, in contrast to more divergent ideations while listening, defined as a highly time-critical process because of its very insertion in time, and because of the limitation of the listener's capacity to process all acoustic stimuli [124] - it is more important for composer to think flexibly, defined as the ability to generate divergent ideations from 'shifts of meaning in response to the same given information', and to elaborate their work, defined as 'the production of detail or complexity of information'.

Indeed, in order to create a suitable compositional idea, it is first essential to structure sounds from different perspectives. Second, suitable composed ideas are characterized by the fact that they will be worked out to the smallest detail (elaboration) - one can assume that every smallest detail presupposes separate more divergent ideations. By that it can be concluded, to find the best expression of a composing detail probably caused a huge amount of more divergent ideations to various possible aspects considered. In terms of the divergent production ability: originality, it can be assumed that in order to generate more divergent ideations while composing leading to an original composition - having the potential to be recognized by listeners as original in the meaning of the 'production of responses rare in the population to which the subject belongs, novel, or remotely associated with the given information' presupposes a very lengthy and elaborate P-culturalizedmusical-creativity processing, which first lays the ground for possible later occurring $\mathrm{H}$-creative composition efforts.

Finally, this outline will be completed with the essential statement that as while listening, more divergent ideations are estimated and/or whittled down, combined, or selected consciously or unconsciously by evaluation processes - as or into a most feasible realistic idea (see dashed line in Figure 3 ). This final idea reflects a unique moment, in satisfying the mental organization of the current compositional concept in relation to perceived acoustic stimuli. In turn, it reflects, at this single compositional moment, a more convergent ideation about: first, possible future occurring events; second, their musical meanings; and third, the meanings of their inter-relations.

Consequently, this suggests: processes structuring (compositional) ideas and their development can be characterized as a constant interplay of more convergent ideations and more divergent ideations (see Figure 3). 


\subsubsection{Evaluation}

In the last step, the important role of evaluation processes is outlined, which are in play at the very heart of new musical extrapolations.

At first, the term evaluation defines: the ability to reach decisions, to make decisions, to make judgments concerning a criterion satisfaction. That is, it is the demonstration of the kind of intelligence which allows one to survey the correctness suitability, adequacy, desirability of alternative responses and then to choose the correct alternative actions [76]. Furthermore, often evaluations are misunderstood because when they are recognized, they are typically convergent and critical and not specifically conducive to originality and flexibility [91].

This means, that evaluations are especially important for individuals as they monitor the problem-solving process, such as the evaluation and selection of generated ideas in relation to the overall concept or strategy to reach a goal. Furthermore, to 'make decisions' in a adequate fashion and 'to choose the correct alternative actions' (see above) assumed that evaluations depend on the actual degree of intrinsic activity and motivation, the maturation of predisposed structures, and are further processed based on criteria, activated from experience-based structures.
Especially, experience-based structures are essential for evaluation processes, because based on previous experiencebased structures, new experiences are created, and the knowledge is built which can be used to recognize or evaluate that there exists a gap or a problem which is interesting enough to spend some time on. Based on these definitions, it is proposed three sorts of evaluation processes (see Figure 4) which, each in a different manner, contribute to the meaning creation while music is being listening to composed:

1. Evaluation (marked by the number 1) deciding whether previously generated more convergent ideation is suitable, adequate, or desirable in relation to current socalled organizational structures.

2. Evaluation (marked by the number 3) which, first: estimate and/or whittle down, combine, or select different sorts of generated more divergent ideation as or into a most feasible appropriate more convergent ideation, or, second: construct and find a new problem.

3. A sort of Pre-Evaluation (marked by the bracketed number 2) which defines more divergent ideations as possible solutions for a certain compositional problem, or, defines ideated aspects of acoustic stimuli as appropriate and useful to get closer to solve problems.

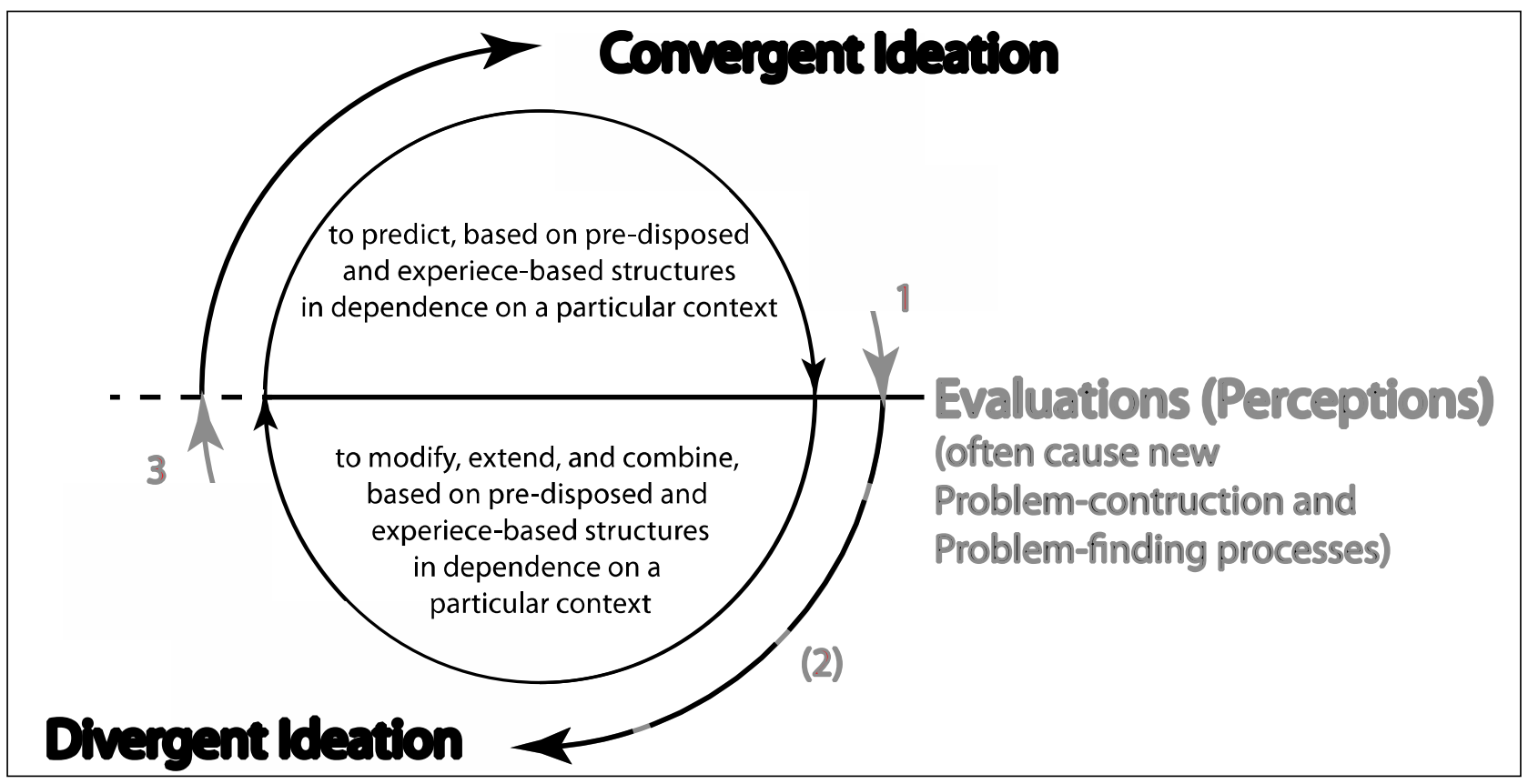

Figure 4. Cyclical interplay of different evaluation processes.

To go more in detail, a so-called problem arises, when a complex of differences or tensions is constructed between previously generated musical extrapolations (representing a sort of goal) and current perceptions and evaluations (comparable to obstacles). This complex of differences or tensions is revealed by a kind of evaluation (marked by the number 1) deciding that previously generated more convergent ideation are inappropriate in relation to current so-called organizational structures.

This means, such processes are caused by the fact that listeners are confronted with ongoing acoustic stimuli, whereby generated ideations about the interpretation of stimuli and their inter-relations must be modified, extended, and combined, driven by the intrinsic activity and motivation to make evaluations concerning a criterion satisfaction (see above). Similarly, until piece related compositional ideations are evaluated as more or less satisfied, generated more convergent ideation - such as a current idea about sound relations, composing strategy, or the overall conception of a piece - needed to be modified, extended, and combined to 
reach the self-imposed final goal, reflected in a completed composition.

Supported by various findings from creativity research (e.g. $[105,48,6,14])$, it should be noticed that evaluations will often be done automatically, and appear to the consciousness only as a reference, such as an affect - when a more convergent ideation does not match current so-called organizational structures. Feist [41] specified for example that intuition is more often used in evaluating a work of art than a work of science. This means that implicit knowledge and criteria are often used to assess art works, and can appear to consciousness as a kind of feeling termed as intuition.

Concerning evaluation processes marked by the number 3 , while listening different sorts of generated ideations about acoustic stimuli can be estimated and/or whittled down, combined, or selected - consciously or unconsciously - by evaluation processes as or into a most feasible appropriate more convergent ideation. This mental product indeed 'predicts' future occuring events, their meanings, and the meanings of their inter-relations; or, second: a new problem is constructed or discovered. Second, based on examples illustrating evaluation processes in conscious (Beethoven, cited in [108]) and unconscious (Haydn, cited in [31]) way, it can be defined that as for listening, evaluations while composing music can also estimate and/or whittle down, combine, or select different sorts of generated divergent ideation as or into a most feasible appropriate more convergent ideation. Third, because problem-finding, problem-construction, and idea-generation processes occuring while listening and composing differ significantly in structure, time exposure as well as complexity, one can suggest that composers often are more time independent, and can evaluate generated ideations based on different criteria, and by that, can judge about ideas in more complex fashion. This means, although it is possible that listeners can evaluate music under the criteria of originality or H-musical creativity, their involvement in a highly time-critical progression and the limitation of the their capacity to process all acoustic stimuli, suggest that, at least within the process of single-time listening [124], evaluations of generated divergent (and convergent) ideations will at first be done among criteria, such as relevance, appropriateness, usefulness to solve problems of understanding about organizational structures of music being listened, before these appropriate and useful ideations can be judged in a more complex fashion, such as in terms of orginality or H-musical creativity. However, this sometimes lacks the mental capacity related to the flow of time while listening to music. In the end, it is essential to state that during more divergent ideation processes, evaluations (marked by the bracketed number 2) also contribute to the meaning creation. This means that, in the case when divergent ideations at hand for the purpose of whittling down, combine, or select among them into a most feasible appropriate more convergent ideation (marked by the number 3), a kind of pre-evaluation is presupposed, which defines these ideations as possible solutions for a certain compositional problem, or, defines ideated aspects of acoustic stimuli as appropriate and useful to get closer to the solution of understanding while listening.

\section{Conclusion}

Based on the interdisciplinary perspectives of the cognitive sciences: developmental psychology, neuroscience, music psychology, emotions research, and creativity research in general and in music, it was presented a systematic understanding about the conditions, mechanisms, influences, and processes evolving into a creative behavior in music.

For instance, findings suggest that general creative processes are involved while music is perceived, learned, and practiced. A further essential perspective shown by this model, is that psychological development of musical abilities consists in far more than enculturalization and acculturalization processes. It was defined such a course of development as processes of P-culturalized-musical creativity, which take place in a kind of a cyclical interplay of processes included in both definitions of musical extrapolations. Indeed, these findings suggest that individuals' understanding of music as a cultural product is a highly active engagement to construe variations of it. In other words, without the creative processes involved, no new compositions could be created by composers, and no psychological development could take place while music is being listened to and composed.

In addition, this so-called Model of Musical Extrapolations could open new perspectives in research, and furthermore, could provide an enormous potential for future extensions, not least because an enhanced perspective is opened about the complexity of highly creative and parallel processes organizing sounds while listening to what is called music, as well as musical ideas while composing.

For example, systematical musicology has developed methods and techniques which analyze composing processes. One of the most established technique investigates composing sketches, fragments of composers, with which music analysts try to reconstruct compositional problem solutions. This means that, through series of notational sketches, preparatory work, fragments and early versions, the development of a musical work could be understood. Moreover, it should be possible to reconstruct the sequence of thoughts which has taken place between two successive notational sketches. However, in fact, incomplete source material can sustainably distort the hypotheses and evidence. In addition, the presented Model of Musical Extrapolations formulates indications to the fact that robust conclusions leading from notational sketches to their source in musical thoughts do not seem scientifically reliable. Not the least because, as it was shown, the processes resorted to by composers to find the best expression of a certain music structure, cause the formation of a huge amount of related but varied musical thoughts.

Based on the framework of the outlined Model of Musical Extrapolations, a research subject is proposed which would empirically investigate the problem-solving processes of 
contemporary composers. This should allow to get closer to a reliable conclusion about those thoughts and processes which evolve into particular artistic results, e.g. notational sketches. Indeed, one can assume that, while composing, the cyclical interplay of problem-construction and problem-finding processes, convergent and divergent ideations, and evaluations are fundamentally organized by activated socalled experience-based structures.

Consequently, a comprehensive detection of these experience-based structures - becoming visible in form of strategies used while composing - could help to get a more reliable insight in processes and thoughts of composers, relatively to limited conclusions deduced from notational sketches. Furthermore, such a comprehensive investigation of strategies used by composers could include a collection of contemporary composers' musical preferences, education and composing experience, motivational aspects, as well as their general creative potential and personality traits. These insightful data could then be used to formulate a taxonomy which can encompass and define composers' problemsolving strategies, and, furthermore, structure an extended knowledge in terms of composers' creative potential, their personality traits, and everyday work context. This taxonomy could ultimately produce a precious knowledge and useful tool for systematical musicology in its attempts to trace back from musical compositions to their generative processes.

Another promising domain of investigation could be pursued in music education research. Indeed, individuals' development is inseparably connected to creative processes. This means that individuals' development in dealing with music (not only) is highly effected by so-called organizational structures detected from the environmental pressure. That is to say parents, caregivers, siblings, inner family life, musical mentors and role models have a crucial impact on children's and students' available organizational structures, and, by that, influence the directions of the created personal environmental pressures. Therefore, within the context of higher music education, a possible research subject could investigate, first: if explicitly presented knowledge from creativity research (e.g. models, strategies) has positive effects on the development of composers' abilities. This means whether abstract and concrete concepts of (musical) creativity can be implemented in the training of individual artists, and can hence be transformed into applicable knowledge.

Second, because flexibility could be outlined as a key feature, which, formally or informally stimulated by parents, caregivers, siblings, musical mentors and role models, can foster individuals' P-culturalized-musical creativity, and, it is common sense that composing mentors serve both as models for behaviors and strategies, and also as sources of information, a further research project could investigate the application and implementation of pedagogical concepts and techniques in secondary education, in order to stimulate and enhance the flexibility of composition students.

There are certainly other possibilities of investigations, which can specify and extend the outlined Model of Musical Extrapolations, and outline new horizons in research besides the perspectives sketched above.

A possible promising extension of this Model might be the integration of concepts from personality research, as it was conceptualized listeners and composers as so-called individuals (see Figure 2), representing a complex of basic factors and processes involved while music is being listened to and composed. Furthermore, it was emphasized the fundamental character of experience itself. It is the groundwork for individuals' further development: based on previous experience-based structures, new experiences are created, and the knowledge is built which can be used to recognize that there exists a gap or a musical problem which is interesting enough to spend some time on. Again, experience can only be created in cooperation with predisposed structures, because humans base their extrapolation processes and, by that, their exploration of acoustical environments on so-called pre-disposed structures. However, based on the discussed studies regarding infants' auditory sensitivities and their general musical organization abilities, it was seen that these pre-disposed structures do not work in all infants in the same way. This suggests that individual differences in processing of pre-disposed structures must be more clearly studied within the proposed Model of Musical Extrapolations.

Therefore, the integration of more aspects of sensitive variability within the framework could be done by incorporating concepts of personality research (e.g. [5, 90, $34,109,88]$ ), instead of the concept of individual (see Figure 2 ). With the help of knowledge from personality research and differences in sensitivities, forms of super-ordinated behavior aspects could be integrated and expressed, e.g. nonconventional thinking, playfulness, anxiety, impulsity. Such a super-ordinated perspective on the processing of musical extrapolations could then open new possibilities within musical research and to other fields.

\section{References}

[1] Anderson, J. R. (1983). The architecture of cognition. Cambridge: Cambridge University Press.

[2] Anderson, J. R. (2009). Cognitive psychology and ist implications, 7th edition. Basingstoke: Palgrave Macmillan.

[3] Akiskal, H. S. \& Akiskal, K. (1988). Significance and artistic creativity. Psychiatry and Psychobiology, 3, (29-36).

[4] Albert, R. S. (1990). Identity, experiences, and career choice among the exceptionally gifted and eminent. In M. A. Runco \& R. S. Albert (Eds.), Theories of creativity (13-34). NewYork: Sage.

[5] Alter, J. B. (1989). Creativity profile of university and conservatory music students. Creativity Research Journal, 2, (184-195).

[6] Arieti, S. (1976). Creativity: The magic synthesis. New York: Basic Books. 
[7] Bailes, F., Bishop, L., Collins, Dave, editor: Chap. Musical imagery in the creative process. In The act of musical composition. Ashgate, 2012, (53-77).

[8] Baron, R. A. (1987). Interviewer's mood and reactions to job applicants: The influence of affective states on applied social judgments. Journal of Applied Social Psychology, 17, (911926).

[9] Bennett, S. (1976). The process of musical creation: Interviews with eight composers. Journal of Research in Music Education, 24, (3-12).

[10] Bjorklund, D. F. (2004). Children's thinking. Belmont: Wadsworth Publishing.

[11] Blaney, P. H. (1986). Affect and memory: A review. Psychological Bulletin, 99, (229-246).

[12] Boden, M. (1994). What is creativity? In M. Boden (Eds.), Dimensions of creativity (75-118). Cambridge, MA: MIT Press.

[13] Bower, G. H. (1992). How might emotions affect learning? In S. A. Christianson (Eds.), The handbook of emotion and memory (3-31). Mahwah: Erlbaum.

[14] Bowers, K. S., Regehr, G., Balthazard, C. \& Parker, K. (1990). Intiution in the context of discovery. Cognitive Psychology, $22,(72-110)$.

[15] Bregman, A. S. (1994). Auditory scene analysis: The perceptual organization of sound. Cambridge, MA: MIT Press.

[16] Burnhard, P. \& Younker, B. A. (2002). Mapping pathways: Fostering creativity in composition. Music Education Research, 4 (2), (245-261).

[17] Burnhard, P. \& Younker, B. A. (2004). Problem-solving and creativity: Insights from students' individual composing pathways. International Journal of Music Education, 22, (5976).

[18] Campos, J. J., Campos, R. G. \& Barrett, K. C. (1989). Emergent themes in the study of emotional development and emotion regulation. Developmental Psychology, 25, (394402).

[19] Canli, T., Zhao, J., Brewer, J., Gabrieli, J. \& Cahill, L. (2000). Event-related activation in the human amygdala associates with later memory for individual emotional reponse. Journal of Neuroscience, 20, (99-107).

[20] Clyman, R. B. (1991). The procedural organization of emotions: A contribution from cogntive science to the psychoanalytic theory of therapeutic action. Journal of the American Psychoanalytic Association, (349-382).

[21] Collins, M. A. \& Amabile, T. M. (1999). Motivation and creativity. In R. J. Sternberg (Eds.), Handbook of creativity (297-312). Cambridge: Cambridge University Press.

[22] Collins, M. A. \& Amabile, T. M. (1999). Motivation and creativity. In R. J. Sternberg, Handbook of creativity. Cambridge: Cambridge University Press.

[23] Collins, D. \& Dunn, M. (2011). Problem-solving strategies and processes in musical composition: Observations in real time. Journal of Music, Technology and Education, 4 (1), (47-76).

[24] Copland, A., Kostelanetz, R. \& Silverstein, S. (2004). Aaron Copland: Selected writings. London: Routledge.
[25] Csikszentmihalyi, M. \& Getzels, J. W. (1971). Discoveryoriented behavior and the orginality of creative products: A study with artists. Journal of Personality and Social Psychology, 19, (47-52).

[26] Damazio, A. (2010). Self comes to mind: Constructing the conscious brain. New York: Pantheon Books.

[27] Danuser, H. \& Katzenberger, G. (1993). Vom Einfall zum Kunstwerk (transl. From thought to work of art). Regensburg: Laaber.

[28] DeCasper, A. J., Spence, M. J. (1986). Newborns prefer a familiar story over unfamiliar one. Infant Behavior and Development, 9, (133-150).

[29] Deliège, I. (2006). Analogy: Creative support to elaborate a model of music listening. In I. Deliège \& G. A. Wiggins, Musical creativity - Multidisciplinary research in theory and practice. New York: Psychology Press.

[30] DeNora, T. (2011). Music in everyday life. New York: Cambridge University Press.

[31] Dies, A. C. (1810). Biographische Nachrichten von Joseph Haydn (transl. Biographical news about Joseph Haydn). Wien: Camesina.

[32] Donohue, R. L. \& Berg, W. K. (1991). Infant heart-rate responses to temoporally predictable and unpredictable events. Developmental Psychology, 27 (1), (59-66).

[33] Draganowa, R., Eswaran, H., Murphy, P., Lowery, C., \& Preissl, H. (2007). Serial magnetoencephalographic study of fetal and newborn auditory discriminative evoked responses. Early Human Development, 83, (199-207).

[34] Dudek, S. Z., Bernèche, R., Bérubé \& Royer, S. (1991). Personlity determinants of the commitment to the profession of art. Creativity Research Journal, 4, (367-389).

[35] Dunn, R. E. (1997). Creative thinking and music listening. Research Studies in Music Education, 8, (42-55).

[36] Edelman, G. (1989). The remembered present: A biological theory of consciousness. New York, NY: Basic Books.

[37] Edelman, G. (1992). Bright air, brilliant fire: On the matter of mind. New York, NY: Basic Books.

[38] Eich, E. (1995). Searching for mood dependent memory. Psychological Science, 6, (67-75).

[39] Elliot, D. J. (1995). Music matters - A new philosophy of music education. Oxford: Oxford University Press.

[40] Feinberg, S. (1974). Creative problem-solving and the music listening experience: Ideas for an approach. Music Educators Journal, 61, (53-60).

[41] Feist, G. J. (1991). Synthetic and analytic thought: Similarities and differences among art and science students. Creativity Research Journal, 4, (145-155).

[42] Feist, G. J. (1999). Affect in artistic and scientific creativity. In S. W. Russ (Eds.), Affect, creative experience, and psychological adjustment (93-109). Philadelphia: Brunner and Mazel.

[43] Forgas, J. P. (1995). Mood and judgement: The affect infusion model (AIM). Psychological Bulletin, 117, (39-66). 
[44] Forgas, J. P., Bower, G. H. \& Krantz, S. (1984). The influence of mood on perceptions of social interactions. Journal of Experimental Social Psychology, 20, (497-513).

[45] Granier-Deferre, C., Bassereau, S., Jacquet, A. Y. \& Lecanuet, J. P. (1998). Fetal and neonatal cardiac orienting response to music in quit sleep. Developmental Psychobiology, 33, (372379).

[46] Granier-Deferre, C., Bassereau, S., Ribeiro, A., Jaquet, A. Y. \& DeCasper, A. J. (2011). A melodic contour repeatedly experienced by human near-term fetuses elicits a profound cardia reaction one month after birth. PlosOne, 6 (2), (1-10).

[47] Goetzel, V. \& Goetzel, M. G. (1962). Cradles of eminence. New York: Little, Brown and Company.

[48] Gruber, H. E. (1988). The evolving systems approach to creative work. Creativity Research Journal, 1, (27-51).

[49] Guilford, J. P. (1967). The nature of human intelligence. New York: McGraw-Hill.

[50] Hargreaves, D. (1996). The development of artistic and musical competence. In I. Deliège and J. A. Sloboda (Eds.), Musical Beginnings (145-170). New York. Oxford University Press.

[51] Hargreaves, D. J., Miell, D. E. \& MacDonald R. A. R. (2012). Musical imagination: Multidisciplinary perspectives on creativity, performance, and perception. Oxford: Oxford University Press.

[52] Hawkins, J. \& Blakeslee, S. (2004). On intellegence. Nw York: Owl Books.

[53] Hayes, J. R. (1985). Three problems in teaching general skills. In S. F. Chipman, Segal, J. W. \& R. Glaser, Thinking and learning skills: Research and open questions. Mahwah: Erlbaum.

[54] He, C. \& Trainor, L. J. (2009). Finding the pitch of the missing fundamental in infants. The Journal of Neuroscience, 29, (7718-7719).

[55] Hepper, P. G. \& Shahidullah, B. S. (1994). Development of fetal hearing. Archives of Disease in Childhood, 71, (81-87).

[56] Holyoak, K. J. (1984). Mental models in problem solving. In J. R. Anderson \& K. M. Kosslyn (Eds.), Tutorials in learning and memory (193-218). San Francisco: Freeman and Company.

[57] Horimoto, N., Hepper, P. G., Shahidullah, S. \& Koyanagi, T. (1993). Fetal eye movements. Ultrasound Obstet Gynecol, 3, (362-369).

[58] Huron, D. (2006). Sweet anticipation: Music and the psychology of expectation. Cambridge, MA: MIT Press.

[59] Kandel, E. R.: The Age of Insight. Random House, 2012.

[60] Katz, S. L. \& Gardner, H. (2012). Musical materials or metaphorical models? In D. Hargreaves, D., Miell, D. \& MacDonald, R., Musical imagination: Multidiciplinary perspectives on creativity, performance, and perception. Oxford: Oxford University Press.

[61] Kiehn, M. T. (2003). Development of music creativity among elementary schools student. Journal of Research in Music Education, 51, (278-288).

[62] Koelsch, S. (2013). Brain and Music. Chichester: John Wiley $\&$ Sons.
[63] Koelsch, S., Gunter, T. C., Friederici, A. D. (2000). Brain indices of music processing: 'Nonmusicians' are musical. Journal of Cognitive Neuroscience, 13, (520-541).

[64] Kozuma, S., Nemoto, A., Okai, T. \& Mizuno, M. (1991). Maturational sequence of fetal breathing movements. Biology of the Neonate, 60, (36-40).

[65] Kisilevsky, B. S., Hains, S. M. J., Lee, K, Xie, X., Huang, H., Ye, H. H., Zhang, K. \& Wang, Z. (2003). Effects of Experience on Fetal Voice Recognition. Psychological Science, 14, (219-224).

[66] Kisilevsky, B. S., Hains, S. M. J., Jacquet, A. Y., GranierDeferre, C. \& Lecanuet, J. P. (2004). Materation of fetal responses to music. Developmental Science, 7 (5), (550-559).

[67] Kivy, P. (2001). Introduction to a philosophy of music. New York: Oxford University Press.

[68] Krumhansl, C. L. \& Jusczyk, P. W. (1990). Infants perception of phrase structure in music. Psychological Science, 1, (70-73).

[69] Kujula, T., Tervaniemi, M. \& Schröger, E. (2007). The mismatch negtivity in cognitive and clinical neuroscience: Theoretical and methodological considerations. Biological Psychology, 74, (1-17).

[70] Lecanuet, J. P., Granier-Deferre, C., Jacquet, A. Y. \& DeCasper, A. J. (2000). Fetal discrimination of low-pitched musical notes. Developmental Psychobiology, 36, (29-39).

[71] LeDoux, J. (1996). The emotional brain. New York: Simon and Schuster.

[72] Lengle, J. M., Chen, M. \& Wakai, R. T. (2001). Improved neuromagnetic detection of fetal and neonatal auditory evoked responses. Clinical Neurophysiology, 112, (785-792).

[73] Martin, L. L., Ward, D. W., Achee, J. W. \& Wyer, R. S. Mood as input: People have to interpret the motivational implications of their moods. Journal of Personality and Social Psychology, 64, (317-326).

[74] Maturana, H. \& Varela, F. (1991, org. 1980). Autopoiesis and cognition: The realization of the living. Berlin: Springer.

[75] McPherson G. E. (2009). The child as musician - A handbook of musical development. New York: Oxford University Press.

[76] Meeker, R. (1980). An advanced SOI test for critical and analytical thinking. Vida: SOI Systems.

[77] Montgomery, C. R. \& Clarkson, M. G. (1997). Infants' perception of pitch: masking by low- and high-frequency noises. Journal of the Acoustical Society of America, 102, (3665-3672).

[78] Mumford, M. D., Baughman, W. A., Threlfall, V., Uhlman, C. E. \& Constanza, D. P. (1993). Personality, adapitvity and performance: Performance on well-defined and ill-defined problem-solving tasks. Human Performance, 6, (241-285).

[79] Mumford, M. D., Reiter-Palmon, R. \& Redmond, M. R. (1994). Problem construction and cognition: Applying problem representations in ill-defined domains. In M. A. Runco, Problem finding, problem solving, and creativity. New York: Ablex.

[80] Nadal, L. \& Zola-Morgan, S. (1984). Infantile amnesia. In M. Moscovitch (Eds.), Infant memory (145-172). New York: Plenum. 
[81] Nakamura, J. \& Csikszentmihalyi, M. (2003). Creativity in later life. In, Creativity and development (186-216). Oxford: Oxford University Press.

[82] Niedenthal, P. M. (2007). Embodying emotion. Science, 316, (1002-1005).

[83] Olsho, L. W. (1987). Level and age effects in infant frequency discrimination. Journal of the Acoustical Society of America, 82 (2), (454-464).

[84] Perazzo, L. M., Moore, J. K. \& Braun, A. (1995). Ontogeny of the human brain stem auditory pathways. Hearing Research, $87,(21-31)$

[85] Peterson, E. M. (2006). Creativity in music listening. Arts Education Policy Review, 107, (15-21).

[86] Piaget, J. (1951). Play, Dreams and Imitation in Childhood. New York: Norton \& Co.

[87] Piaget, J. (1952). The origins of intelligence in children. Madison: International Universities Press.

[88] Policastro, E. \& Gardner, H. (1999). From case studies to robust generalizations: An approach to the study of creativity. In R. J. Sternberg, Handbook of creativity. Cambridge University Press.

[89] Priest, T. (2001). Using creativity assessment experience to nurture and predict compositional creativity. Journal of Research in Music Education, 29 (3), (245-257).

[90] Rothenburg, A. (1990). Creativity and madness: New findings and old stereotypes. Baltimore: John Hopkins University Press.

[91] Runco, M. A. \& Chand, I. (1995). Cognition and creativity. Educational Psychology Review, 7, (243-267).

[92] Russ, S. W. (1993). Affect and creativity: The role of affect and play in the creative process. Mahwah: Erlbaum.

[93] Russell, J. A. (2003). Core affect and the psychological construction of emotion. Psychological Review, 110 (1), 145172.

[94] Runco, M. A. (2007). Creativity - Theories and themes: Research, development, and practice. San Diego: Elsevier.

[95] Runco, M. A., McCarthy, K. A. \& Svenson, E. (1994). Judgements of the creativity of artwok from students and professional artists. The Journal of Psychology, 128, (23-31).

[96] Schacter, D. L. \& Moscovitch, M. (1984). Infants, amnesia and dissiciable memory systems. In M. Moscovitch (Eds.), Infant memory (173-216). New York: Plenum.

[97] Schaeffer, P. (1966). Traité des objets musicaux - Essai interdisciplines. Paris: Éditions du Seuil.

[98] Schmidt, S., Troge, T. A. \& Lorrain, D. (2013). Musical probabilities, abductive reasoning, and brain mechanisms: Extended perspective of apriori listening to music within the creative cognition approach. Creativity Research Journal, 25, (259-265).

[99] Schraw, G., Dunkle, M. E. \& Bendixen, L. D. (1995). Cognitive processes in well-defined and ill-defined problem solving. Applied Cognitive Psychology, 9, (523-538).

[100] Schubert, E. \& McPherson, G. E. (2006). The perception of emotion in music. In G. E. McPherson (Eds.), The child as musician - a handbook of musical development (193-212). Oxford: Oxford University Press.

[101] Schuldberg, D. (1990). Schizotypal and hypomanic traits, creativity, and psychological health. Creativity Research Journal, 3, (218-230).

[102] Schuldberg, D. (1999). Creativity, bipolarity, and the dynamics of style. In S. W. Russ (Eds.), Affect, creative experience, and psychological adjustment. Philadelphia: Brunner and Mazel.

[103] Shapiro, P. J. \& Weisberg, R. W. (1999). Creativity and bipolar diathesis: Common behavioral and cognitive components. Cognition and Emotion, 13, (741-762).

[104] Shapiro, P. J. (2000). Creativity and bipolarity: Affective patterns predict trait creativity. In Proceedings of the Convention of the American Psychological Society, Miami.

[105] Smith, S. \& Blankenship, S. (1989). Incubation effects. Bulletin of the Psychonomic Society, 27, (311-314).

[106] Smith, S. M. \& Ward, T. B. \& Finke, R. A. (1992). Creative cognition: Theory, research, and applications. Cambridge, MA: MIT Press.

[107] Snyder, B. (2000) Music and Memory: An Introduction. Cambridge, MA: MIT Press.

[108] Sloboda, J. A (1985). The musical mind. Oxford: Oxford University Press.

[109] Sternberg, R. J. \& Lubert, T. I. (1995). Defying the crowd: Cultivating creativity in a culture of conformity. New York: Free Press.

[110] Swanwick, K. \& Tillman, J. (1986). The sequence of musical development: A study of children's composition. British Journal of Music Education, 3 (3), 305-339.

[111] Tafuni, J. (2006). Processes and teaching strategies in musical improvisation with children. In I. Deliège \& G. A. Wiggins (Eds.), Musical Creativity - Multidisciplinary Research in Theory and Practice (134-157). New York: Psychology Press.

[112] Tew, S., Fujioka, T., He, C. \& Trainor, L. J. (2009). Neural representation of transposed melody in infants at 6 months of age. Annals of the New York Academy of Sciences, The Neuroscience of Music III: Disorders and Plasticity, (287-290).

[113] Thelen, E. (1979). Rhythmical stereotypies in normal human infants. Animal Behavior, 27 (3), (699-715).

[114] Trainor, L. J. \& Zatorre, R. J. (2009). The neurobiological basis of musical expectations. In S. Hallam, I. Cross \& M. Thaut (Eds.), The oxford handbook of music psychology (171-183). Oxford: Oxford University Press.

[115] Trehub, S. E. (1973). Infants's sensitivity to vowel and tonal contrasts. Developmental Psychology, 9 (1), (91-96).

[116] Trehub, S. E., Schneider, B. A. \& Endman, M. (1980). Developmental changes in infants' sensitivity to octave-band noises. Journal of Experimental Child Psychology, 29, (282293).

[117] Trehub, S. E., Endman, M. W. \& Thorpe L. A. (1990). Infants' perception of timbre: Classification of complex. Journal of Experimental Child Psychology, 49, (300-313). 
[118] Tuuri, K. \& Eerola, T. (2012). Formulating a revised taxonomy for modes of listening. Journal of New Music Research, 41 (2), (137-152).

[119] Van Hereren, C. F., Boekkooi, P. F., Jongsma, H. W. \& Hijhuis, J. P. (2000). Fetal learning and memory, Lancet, 356, (1169-1170).

[120] Wakai, R. T., Leuthold, A. C. \& Martin, C. B. (1996). Fetal auditory responses detected by magnetoencephalography. American Journal of Obstetrics and Gynecology, 174, (14841486).

[121] Wallas, G. (1926). The art of thought. San Diego: Harcourt, Brace, and Company.

[122] Wakefield, J. (1992). Creative thinking: Problem solving skills and arts orientation. New York: Ablex.

[123] Webster, P. (1979). Relationship between creative behavior in music and selected variables as measured in high school students. Journal of Research in Music Education, 27 (4), (227-242).

[124] Webster, P. (2002). Creative thinking in music: Advancing a model. In T. Sullivan \& L. Willingham (Eds.), Creativity in Music Education (Research to practice: CMWA biennial series). Canadian Music Educators' Association.
[125] Webster, R. (2003). What do you mean, make my music different? Encouraging revision and extensions on children's music composition. In M Hickey (Eds.), Why and how to teach music composition: A new horizon for music education. Lanham: Rowman and Littlefield.

[126] Welling, H. (2007). Four Mental Operations in Creative Cognition: The Importance of Abstraction. Creative Research Journal, 19 (2), (163-177).

[127] Werner, L. A., Folsom, R. C. \& Manel, L. R. (1993). The relationship between auditory brainstem response and behavioral thresholds in normal hearing infants and adults. Hearing Research, 68, (131-141).

[128] Wertheimer, M. (1922). Untersuchungen zur Lehre von der Gestalt. Psychologische Forschung, 1, (47-58).

[129] Winkler, I., Kushnerenko, E., Horváth, J., Ceponiené, R., Fellman, V., Huotilainen, M., Näätänen, R., \& Sussman, E. (2003). Newborn infants can organize the auditory world. Proceedings of the National Academy of Sciences USA, 100 (20), (11812-11815).

[130] Woodman, R. W. \& Schoenfeldt, L. F. (1990). An interactionist model of creative behavior. Journal of Creative Behavior, 24, (279-297). 